\title{
Response to Clopidogrel and Its Association with Chronic Kidney Disease in Noncardiogenic Ischemic Stroke Patients
}

Hajime Maruyama, Takuya Fukuoka, Ichiro Deguchi, Yasuko Ohe, Yuji Kato, Yohsuke Horiuchi, Takeshi Hayashi, Yuito Nagamine, Hiroyasu Sano and Norio Tanahashi

\begin{abstract}
Objective Noncardiogenic ischemic stroke patients with chronic kidney disease (CKD) are known to have a greater rate of ischemic stroke recurrence than those without. Although clopidogrel is often used to prevent the recurrence of noncardiogenic ischemic stroke, the relationship between the response to clopidogrel and $\mathrm{CKD}$ is unclear. In the present study, the relationship between the response to clopidogrel and the presence of CKD was investigated in noncardiogenic ischemic stroke patients.

Methods A total of 129 noncardiogenic ischemic stroke patients receiving $75 \mathrm{mg} /$ day of clopidogrel for $\geq 1$ week were evaluated. The VerifyNow P2Y12 Assay was used to measure the level of platelet aggregation induced by $20 \mu \mathrm{M}$ of adenosine diphosphate, and the degree of platelet aggregation and frequency of clopidogrel resistance were compared between 34 patients with CKD and 95 patients without CKD. Clopidogrel resistance was defined as a P2Y12 Reaction Units (PRU) value of $>230$ and/or \% inhibition $<20 \%$.

Results The PRU value was 201.9 \pm 91.3 in the patients with CKD and $163.3 \pm 86.4$ in the patients without CKD ( $\mathrm{p}=0.035$ ). The frequency of a PRU value of $>230$ was $44.1 \%$ (15 patients) among the patients with $\mathrm{CKD}$ and $17.9 \%$ (17 patients) among those without CKD ( $\mathrm{p}=0.002)$. The percent inhibition was $29.9 \% \pm$ $28.1 \%$ among the patients with $\mathrm{CKD}$ and $41.1 \% \pm 28.0 \%$ among the patients without $\mathrm{CKD}(\mathrm{p}=0.030)$. The frequency of $\%$ inhibition $<20 \%$ was $47.1 \%$ (16 patients) among the patients with CKD and $26.3 \%$ (25 patients) among those without CKD ( $\mathrm{p}=0.026)$.

Conclusion The present study showed that noncardiogenic ischemic stroke patients with CKD have a greater frequency of clopidogrel resistance, thus suggesting that the response to clopidogrel is diminished in these patients.
\end{abstract}

Key words: clopidogrel resistance, ischemic stroke, chronic kidney disease, VerifyNow P2Y12 Assay

(Intern Med 53: 215-219, 2014)

(DOI: 10.2169/internalmedicine.53.1316)

\section{Introduction}

Chronic kidney disease (CKD) is an independent risk factor for stroke and is known to affect stroke outcomes (1-5). It has also been reported that noncardiogenic ischemic stroke patients with CKD have a higher rate of ischemic stroke recurrence (6). In Japan, the administration of aspirin, clopidogrel and/or cilostazol is recommended to prevent the recurrence of noncardiogenic ischemic stroke. We previously measured the degree of platelet aggregation in noncardiogenic ischemic stroke patients and reported that $8-29 \%$ of the patients had clopidogrel resistance (7-9). Several factors, including genetic polymorphisms of the drug-metabolizing enzyme CYP2C19, have been identified as causes of clopidogrel resistance $(10,11)$. However, the relationship between the antiplatelet effects of clopidogrel and the development of CKD in noncardiogenic ischemic stroke patients has not been elucidated. In this study, the VerifyNow P2Y12 Assay (Accumetrics Inc., San Diego, CA, USA) was used to measure the degree of platelet aggregation in noncardiogenic ischemic stroke patients, and the relationship between the antiplatelet effects of clopidogrel and CKD was investigated. 
Table 1. Baseline Clinical and Laboratory Characteristics

\begin{tabular}{|c|c|c|c|}
\hline Variables & $\begin{array}{c}\text { CKD group } \\
(\mathrm{n}=34)\end{array}$ & $\begin{array}{c}\text { non-CKD group } \\
(\mathrm{n}=95)\end{array}$ & $\mathrm{p}$ value \\
\hline Age (years) & $72.2 \pm 7.9$ & $64.7 \pm 9.4$ & $<0.001$ \\
\hline Male, n (\%) & $27(79.4)$ & $71(74.7)$ & 0.584 \\
\hline BMI $\left(\mathrm{kg} / \mathrm{m}^{2}\right)$ & $24.6 \pm 3.4$ & $23.6 \pm 3.2$ & 0.249 \\
\hline Smoking, n (\%) & $14(41.2)$ & $48(50.5)$ & 0.349 \\
\hline Diabetes mellitus, n (\%) & $13(38.2)$ & $39(41.1)$ & 0.774 \\
\hline Hypertension, n (\%) & $25(73.5)$ & $60(63.2)$ & 0.274 \\
\hline Dyslipidemia, n (\%) & $26(76.5)$ & $64(67.4)$ & 0.321 \\
\hline $\mathrm{HbAlc}(\%)$ & $6.0 \pm 1.4$ & $6.2 \pm 1.8$ & 0.775 \\
\hline $\mathrm{TC}(\mathrm{mg} / \mathrm{dL})$ & $188.4 \pm 28.8$ & $184.7 \pm 38.9$ & 0.729 \\
\hline LDL-C (mg/dL) & $110.2 \pm 33.2$ & $112.5 \pm 36.4$ & 0.805 \\
\hline HDL-C (mg/dL) & $43.6 \pm 10.6$ & $43.6 \pm 16.0$ & 0.694 \\
\hline TG (mg/dL) & $149.3 \pm 68.7$ & $156.7 \pm 81.0$ & 0.824 \\
\hline $\mathrm{sCr}(\mathrm{mg} / \mathrm{dL})$ & $1.32 \pm 0.68$ & $0.75 \pm 0.15$ & $<0.001$ \\
\hline eGFR $\left(\mathrm{mL} / \mathrm{min} / \mathrm{m}^{2}\right)$ & $45.9 \pm 12.9$ & $78.5 \pm 15.9$ & $<0.001$ \\
\hline \multicolumn{4}{|l|}{ Concomitant medications } \\
\hline ARBs, n $(\%)$ & $16(47.1)$ & $36(37.9)$ & 0.350 \\
\hline Statins, n (\%) & $16(47.1)$ & $33(34.7)$ & 0.204 \\
\hline PPIs, n (\%) & $25(73.5)$ & $71(74.7)$ & 0.890 \\
\hline \multicolumn{4}{|l|}{ Clinical stroke type } \\
\hline Atherothrombotic infarction, $\mathrm{n}(\%)$ & $21(61.8)$ & $63(66.3)$ & 0.580 \\
\hline Lacunar infarction, $\mathrm{n}(\%)$ & $10(29.4)$ & $24(25.3)$ & 0.638 \\
\hline Transient ischemic attack, $\mathrm{n}(\%)$ & $3(8.8)$ & $8(8.4)$ & 0.943 \\
\hline
\end{tabular}

BMI: body mass index, HbA1c: hemoglobin A1c, TC: total cholesterol, LDL-C: low-density lipoprotein cholesterol, HDL-C: high-density lipoprotein cholesterol, TG: triglycerides, sCr: serum creatinine, eGFR: estimated glomerular filtration rate, ARB: angiotensin II receptor blocker, PPI: proton pump inhibitor

\section{Materials and Methods}

A total of 129 noncardiogenic ischemic stroke patients (98 men, 31 women, mean age: $66.7 \pm 9.6$ years) $\geq 2$ weeks since onset who had been taking $75 \mathrm{mg} /$ day of clopidogrel for $\geq 1$ week and had been treated at the stroke center of our hospital between October 2009 and November 2012 were evaluated. The clinical stroke types were atherothrombotic infarction (84 patients), lacunar infarction (34 patients) and transient ischemic attack (11 patients). None of the patients were concomitantly using antiplatelet agents aside from clopidogrel.

CKD was defined as a glomerular filtration rate (GFR) of $<60 \mathrm{~mL} / \mathrm{min} / 1.73 \mathrm{~m}^{2}$ or kidney damage for $\geq 3$ months determined based on the presence of urine, blood, imaging or pathological abnormalities according to the Kidney Disease Outcome Quality Initiative (K/DOQI) (12). In Japan, the estimated GFR (eGFR) determined based on the serum creatinine $(\mathrm{sCr})$ level is used to evaluate the renal function and is calculated using the following equation created by the Japanese Society of Nephrology (13): eGFR (mL/min/1.73 $\left.\mathrm{m}^{2}\right)=194 \times \mathrm{sCr}^{-1.094} \times \mathrm{age}^{-0.287}$ (multiply by 0.739 for women). In the present study, after excluding patients with acute kidney injury (AKI), defined as an eGFR of $<60 \mathrm{~mL} / \mathrm{min} / 1.73 \mathrm{~m}^{2}$ at the time of the initial consultation, 34 patients were assigned to the CKD group. In addition, the eGFR measurement values obtained following the improvement of kidney damage were used in patients with AKI.

Table 1 shows the baseline clinical and laboratory characteristics of the 34 patients with and the 95 patients without CKD. Although the patients with CKD were older, there were no significant differences in sex, body mass index (BMI), smoking history, diabetes, hypertension or dyslipidemia between the patients with and those without CKD. Blood test measurements of the levels of HbA1c, total cholesterol, low-density lipoprotein cholesterol, high-density lipoprotein cholesterol and triglycerides also showed no significant differences between the two groups of patients. The concomitant use of angiotensin II receptor blockers, proton pump inhibitors or statins was not significantly different between the two groups. The frequencies of clinical stroke types (atherothrombotic brain infarction, lacunar infarction and transient ischemic attack) were also not different between the groups.

Blood samples $(1.8 \mathrm{~mL})$ were drawn from the patients using $21-\mathrm{G}$ or greater blood collection needles into a vacutainer containing $0.2 \mathrm{~mL}$ of $3.2 \%$ sodium citrate. The VerifyNow P2Y12 Assay was used 10 minutes to four hours after blood collection to measure the degree of platelet aggregation induced by $20 \mu \mathrm{M}$ of adenosine diphosphate (ADP), and the patients were divided into two groups: those with CKD (34 patients) and those without (95 patients). The degree of platelet aggregation and frequency of clopidogrel resistance were compared between the two groups of patients. In addition, to adjust for the effects of age, a multivariate analysis was performed with age, $\mathrm{sCr}$, eGFR and BMI as factors, and the relationships of these factors to clopidogrel resistance were assessed.

\section{Definition of clopidogrel resistance}

Recently, the use of P2Y12 Reaction Units (PRU) as an indicator of clopidogrel resistance has become widespread with the publication of The Gauging Responsiveness With a VerifyNow P2Y12 Assay: Impact on Thrombosis and Safety (GRAVITAS) trial (14). There are also several reports that used the $\%$ inhibition as an indicator. In the present study, clopidogrel resistance was defined as PRU >230 (14-16) and/or \% inhibition <20\% (17-19), based on previous reports.

\section{VerifyNow P2Y12 Assay}

The VerifyNow P2Y12 Assay is an instrument that measures P2Y12 receptor inhibition in platelets using whole blood samples. This assay measures the platelet function based on the ability of activated platelets to bind to fibrinogen. In the measurement cartridges, there are reaction chambers with $20 \mu \mathrm{M}$ of $\mathrm{ADP}+22 \mathrm{nM}$ prostaglandin E1 and isothrombin receptor activating peptide (iso-TRAP) as platelet activating substances, each containing fibrinogen. The fibrinogen molecules aggregate in whole blood proportionate to the number of glycoprotein (GP) IIb/IIIa receptors on activated platelets. Changes in platelet activation are captured by monitoring the changes in light transmittance caused by 


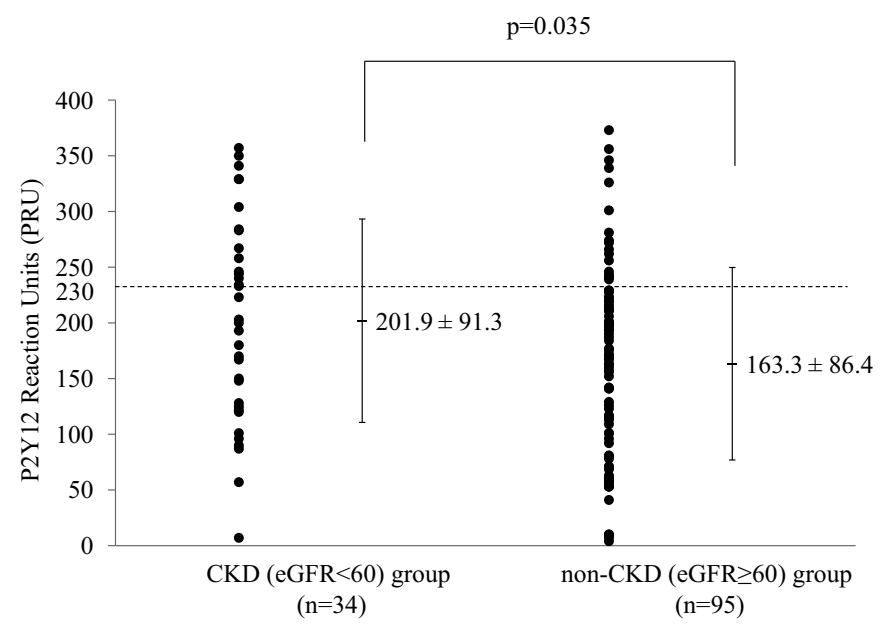

Figure 1. P2Y12 Reaction Units (PRU) results. The PRU values were significantly greater in the chronic kidney disease group. The frequency of a PRU value of $>230$ was also significantly greater in this group.

aggregate formation. The extent of aggregation is expressed in terms of PRU and \% inhibition. The PRU value indicates the amount of aggregation induced by ADP specific to platelet P2Y12 receptors and is calculated based on the speed and extent of platelet aggregation in a reaction chamber containing ADP. The percent inhibition represents the percent change from the baseline aggregation ability and is calculated using the PRU and baseline (BASE) results. The BASE is an independent measurement based on the speed and extent of platelet aggregation induced by thrombin receptors, particularly the protease-activated receptor-1, 4 (PAR-1, 4). Iso-TRAP and PAR-4 activating peptide (PAR-4 $\mathrm{AP})$ are incorporated into the BASE measurement reaction chambers to activate platelets. The percent inhibition is determined by the following equation: $\%$ inhibition $=100 \times$ (BASE-PRU)/BASE.

\section{Statistical analysis}

The IBM SPSS Statistics 20 software package (IBM SPSS Inc., Chicago, IL, USA) was used for the statistical analysis. The Mann-Whitney U test or Pearson's Chi-square test were used to compare the baseline clinical and laboratory characteristics. The Mann-Whitney $U$ test was used to compare the PRU and \% inhibition values. Pearson's Chisquare test was used to compare the frequency of clopidogrel resistance. A multiple logistic regression analysis was used for the multivariate analyses. For all tests, $\mathrm{p}<0.05$ was considered to be significant.

\section{Ethical approval}

This study was approved by the Saitama Medical University Ethics Committee.

\section{Results}

The PRU results are shown in Fig. 1. The patients with CKD had significantly higher PRU values than the patients without CKD ( $\mathrm{p}=0.035)$, with PRU values of 201.9 \pm 91.3 and $163.3 \pm 86.4$, respectively. The frequency of a PRU value of $>230$ was also significantly greater in the patients with CKD (15/34 patients, 44.1\%) than in the patients without CKD (17/95 patients, $17.9 \%)(\mathrm{p}=0.002)$.

The $\%$ inhibition results are shown in Fig. 2. The patients with CKD had a \% inhibition value of $29.9 \% \pm 28.1 \%$, while those without CKD had a \% inhibition value of $41.1 \% \pm$ $28.0 \%$, indicating significantly lower $\%$ inhibition values in the patients with CKD $(\mathrm{p}=0.030)$. The frequency of $\%$ inhibition $<20 \%$ was significantly greater in the patients with CKD (16/34 patients, $47.1 \%)$ than in those without CKD $(25 / 95$ patients, $26.3 \%)(\mathrm{p}=0.026)$.

Table 2 shows the results of the multivariate analysis of the factors associated with a PRU value of $>230$. The results demonstrated that the $\mathrm{sCr}$ and eGFR were associated with a PRU value of $>230$; however, age and BMI were not.

Table 3 shows the results of the multivariate analysis of the factors associated with $\%$ inhibition $<20 \%$. The results indicated that only the eGFR was associated with $\%$ inhibition $<20 \%$.

\section{Discussion}

In the present study, there was a relationship between the renal function and the efficacy of clopidogrel, as well as a higher frequency of clopidogrel resistance with weak platelet aggregation inhibitor action in noncardiogenic ischemic stroke patients with CKD.

Very few reports have investigated the relationship between CKD and the platelet aggregation inhibitor action of clopidogrel. The current study is the first to report such an association in the brain. Previous reports have evaluated patients with coronary artery disease or peripheral artery disease (20-22). For example, Park et al. (20) investigated patients who underwent coronary angiography, coronary vascular intervention or peripheral vascular intervention and 


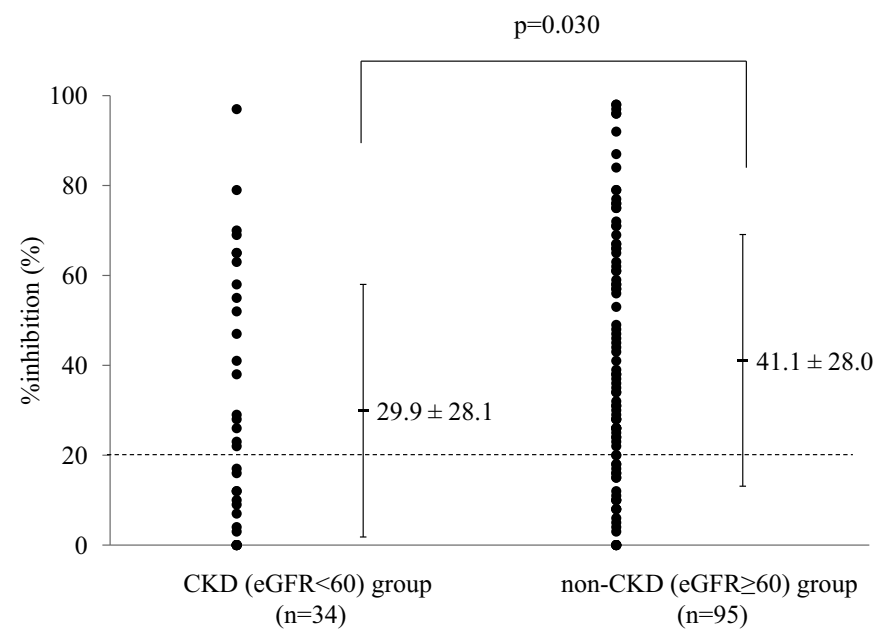

Figure 2. \% inhibition results. Significantly lower \% inhibition values were observed in the chronic kidney disease group. Additionally, the frequency of $\%$ inhibition $<20 \%$ was significantly greater in this group.

Table 2. Factors Associated with a P2Y12 Reaction Units Value of $>\mathbf{2 3 0}$

\begin{tabular}{lccc}
\hline Factors & $\begin{array}{c}\text { PRU }>230 \\
(\mathrm{n}=32)\end{array}$ & $\begin{array}{c}\text { PRU } \leq 230 \\
(\mathrm{n}=97)\end{array}$ & p value \\
\hline Age $($ years $)$ & $69.4 \pm 10.9$ & $65.8 \pm 9.0$ & 0.951 \\
$\mathrm{BMI}\left(\mathrm{kg} / \mathrm{m}^{2}\right)$ & $23.8 \pm 3.7$ & $23.7 \pm 3.2$ & 0.585 \\
$\mathrm{sCr}(\mathrm{mg} / \mathrm{dL})$ & $0.96 \pm 0.37$ & $0.88 \pm 0.47$ & 0.047 \\
$\mathrm{eGFR}\left(\mathrm{mL} / \mathrm{min} / \mathrm{m}^{2}\right)$ & $61.0 \pm 17.6$ & $72.9 \pm 21.0$ & 0.006 \\
\hline
\end{tabular}

BMI: body mass index, sCr: serum creatinine, eGFR: estimated glomerular filtration rate

measured platelet aggregation using the VerifyNow P2Y12 Assay in 23 normal renal function patients receiving $75 \mathrm{mg} /$ day of clopidogrel, $18 \mathrm{CKD}$ patients receiving $75 \mathrm{mg} /$ day of clopidogrel and $18 \mathrm{CKD}$ patients receiving $150 \mathrm{mg}$ /day of clopidogrel. They reported that the patients with CKD exhibited a reduced platelet aggregation inhibitor action induced by clopidogrel and that the antiplatelet effects were not ameliorated, even with a double dose of clopidogrel.

Although the reasons why the antiplatelet effects of clopidogrel are decreased in CKD patients remain unclear, several mechanisms can be postulated from the perspective of drug metabolism and the platelet function. Since clopidogrel is a prodrug, it becomes active and exerts its efficacy after being metabolized by the liver. However, patients with CKD have a decreased expression of drug-metabolizing enzymes, such as CYP2C19, that are involved in clopidogrel metabolism (23-25). Muller et al. (22) reported that the frequency of clopidogrel resistance increases as the renal function decreases. In contrast, Small et al. (26) investigated the effects of prasugrel, a third-generation thienopyridine, in patients with a normal renal function, moderate renal insufficiency and end-stage renal disease and found that the inhibition of platelet aggregation was similar in all patients. In addition, patients with CKD have impaired drug absorption and transport (24). For these reasons, patients with CKD are considered to have a decreased response to clopidogrel, thus lead-
Table 3. Factors Associated with \% Inhibition $<20 \%$

\begin{tabular}{lccc}
\hline Factors & $\begin{array}{c}\text { \%inhibition }<20 \% \\
(\mathrm{n}=41)\end{array}$ & $\begin{array}{c}\text { \%inhibition } \geq 20 \% \\
(\mathrm{n}=88)\end{array}$ & $\mathrm{p}$ value \\
\hline Age $($ years $)$ & $67.8 \pm 10.8$ & $66.1 \pm 8.9$ & 0.976 \\
BMI $\left(\mathrm{kg} / \mathrm{m}^{2}\right)$ & $24.5 \pm 3.8$ & $23.6 \pm 3.0$ & 0.236 \\
$\mathrm{SCr}(\mathrm{mg} / \mathrm{dL})$ & $0.91 \pm 0.35$ & $0.89 \pm 0.49$ & 0.081 \\
eGFR $\left(\mathrm{mL} / \mathrm{min} / \mathrm{m}^{2}\right)$ & $64.6 \pm 18.1$ & $72.5 \pm 21.7$ & 0.029 \\
\hline
\end{tabular}

BMI: body mass index, sCr: serum creatinine, eGFR: estimated glomerular filtration rate

ing to a diminished platelet effect. Furthermore, in patients with CKD, the platelet turnover rate is enhanced due to an increased level of thrombopoietin (27) and the presence of platelet function disorders, such as the degeneration of glycoprotein IIb/IIIa, abnormal release of ADP and serotonin from $\alpha$ granules, changes in prostaglandin metabolism and structural abnormalities of the platelet cytoskeleton (20), which are thought to decrease the response to clopidogrel.

There are several limitations to this study. First, it was not possible to perform comparisons at each stage of CKD due to the small number of patients enrolled in the study. Second, the definition of clopidogrel resistance using the VerifyNow P2Y12 Assay has not yet been established in Japanese patients. The frequency of clopidogrel resistance differs greatly depending on the test method and cutoff value. Therefore, the definition of clopidogrel resistance has yet to be standardized. Third, the formula for eGFR used in this study does not include body weight, unlike the Cockcroft-Gault equation. Lastly, the CYP2C19 genetic polymorphism involved in clopidogrel resistance was not examined in this study. Racial differences in the frequency of CYP2C19 gene mutations have been documented. For example, Asians have been reported to have higher frequencies of the loss-of-function mutations CYP2C $19^{*} 2$ and CYP2C19"3 than Western populations, with many poor metabolizers $(2 / 2, " 2 / 3,3 / 3)(28)$. Therefore, investigating genetic polymorphisms is necessary in the future. 
In conclusion, the present study showed that noncardiogenic ischemic stroke patients with CKD have a greater frequency of clopidogrel resistance, thus suggesting that the response to clopidogrel is reduced in these patients.

The authors state that they have no Conflict of Interest (COI).

\section{References}

1. Anaverkar NS, McMurray JJ, Velazquez EJ, et al. Relation between renal dysfunction and cardiovascular outcomes after myocardial infarction. N Engl J Med 351: 1285-1295, 2004.

2. Nakayama M, Metoki H, Terawaki H, et al. Kidney dysfunction as a risk factor for first symptomatic stroke events in a general Japanese population: the Ohasama study. Nephrol Dial Transplant 22: 1910-1915, 2007.

3. Irie $\mathrm{F}$, Iso $\mathrm{H}$, Sairenchi $\mathrm{T}$, et al. The relationships of proteinuria, serum creatinine, glomerular filtration rate with cardiovascular disease mortality in Japanese general population. Kidney Int 69: 1264-1271, 2006

4. Nickolas TL, Khatri M, Boden-Albala B, et al. The association between kidney disease and cardiovascular risk in a multiethnic cohort: findings from the Northern Manhattan Study (NOMAS). Stroke 39: 2876-2879, 2008.

5. Yahalom G, Schwartz R, Schwammenthal Y, et al. Chronic kidney disease and clinical outcome in patients with acute stroke. Stroke 40: 1296-1303, 2009.

6. Kuwashiro T, Sugimori H, Ago T, Kamouchi M, Kitazono T; FSR Investigators. Risk factors predisposing to stroke recurrence within one year of non-cardioembolic stroke onset: the Fukuoka Stroke Registry. Cerebrovasc Dis 33: 141-149, 2012.

7. Fukuoka T, Furuya D, Takeda H, et al. Evaluation of clopidogrel resistance in ischemic stroke patients. Intern Med 50: 31-35, 2011.

8. Maruyama H, Takeda H, Dembo T, et al. Clopidogrel resistance and the effect of combination cilostazol in patients with ischemic stroke or carotid artery stenting using the VerifyNow P2Y12 Assay. Intern Med 50: 695-698, 2011.

9. Maruyama H, Fukuoka T, Deguchi I, et al. Dual antiplatelet therapy clopidogrel with low-dose cilostazol intensifies platelet inhibition in patients with ischemic stroke. Intern Med 52: 1043-1047, 2013.

10. Angiolillo DJ, Fernandez-Ortiz A, Bernardo E, et al. Variability in individual responsiveness to clopidogrel: clinical implications, management, and future perspectives. J Am Coll Cardiol 49: 1505-1516, 2007

11. Hulot JS, Bura A, Villard E, et al. Cytochrome P450 2C19 lossof-function polymorphism is a major determinant of clopidogrel responsiveness in healthy subjects. Blood 108: 2244-2247, 2006.

12. National Kidney Foundation. K/DOQI clinical practice guidelines for chronic kidney disease: evaluation, classification, and stratification. Am J Kidney Dis 39: S1-S266, 2002.

13. Matsuo S, Imai E, Horio M, et al; Collaborators developing the Japanese equation for estimated GFR. Revised equations for esti- mated GFR from serum creatinine in Japan. Am J Kidney Dis 53: 982-992, 2009.

14. Price MJ, Angiolillo DJ, Teirstein PS, et al. Platelet reactivity and cardiovascular outcomes after percutaneous coronary intervention: a time-dependent analysis of the Gauging Responsiveness with a VerifyNow P2Y12 assay: Impact on Thrombosis and Safety (GRAVITAS) trial. Circulation 124: 1132-1137, 2011.

15. Brar SS, ten Berg J, Marcucci R, et al. Impact of platelet reactivity on clinical outcomes after percutaneous coronary intervention. A collaborative meta-analysis of individual participant data. J Am Coll Cardiol 58: 1945-1954, 2011.

16. Ueno M, Ferreiro JL, Tomasello SD, et al. Impact of pentoxifylline on platelet function profiles in patients with type 2 diabetes mellitus and coronary artery disease on dual antiplatelet therapy with aspirin and clopidogrel. JACC Cardiovasc Interv 4: 905-912, 2011.

17. Kim JY, Lee K, Shin M, et al. Cilostazol could ameliorate platelet responsiveness to clopidogrel in patients undergoing primary percutaneous coronary intervention. Circ J 71: 1867-1872, 2007.

18. Shim CY, Yoon SJ, Park S, et al. The clopidogrel resistance can be attenuated with triple antiplatelet therapy in patients undergoing drug-eluting stents implantation. Int J Caidiol 134: 351-355, 2009.

19. Jin EZ, Yu LH, Li XQ. Loading effect of $200 \mathrm{mg}$ cilostazol on platelet inhibition in patients undergoing percutaneous coronary intervention. Int Heart J 53: 1-4, 2012.

20. Park SH, Kim W, Park CS, Kang WY, Hwang SH, Kim W. A comparison of clopidogrel responsiveness in patients with versus without chronic renal failure. Am J Cardiol 104: 1292-1295, 2009.

21. Angiolillo DJ, Bernardo E, Capodanno D, et al. Impact of chronic kidney disease on platelet function profiles in diabetes mellitus patients with coronary artery disease taking dual antiplatelet therapy. J Am Coll Cardiol 55: 1139-1146, 2010.

22. Muller C, Caillard S, Jesel L, et al. Association of estimated GFR with platelet inhibition in patients treated with clopidogrel. Am J Kidney Dis 59: 777-785, 2012.

23. Touchette MA, Slaughter RL. The effect of renal failure on hepatic drug clearance. DICP 25: 1214-1224, 1991.

24. Leblond F, Guevin C, Demers C, Pellerin I, Gascon-Barré M, Pichette V. Downregulation of hepatic cytochrome P450 in chronic renal failure. J Am Soc Nephrol 12: 326-332, 2001.

25. Dreisbach AW. The influence of chronic renal failure on drug metabolism and transport. Clin Pharmacol Ther 86: 553-556, 2009.

26. Small DS, Wrishko RE, Ernest CS 2nd, et al. Prasugrel pharmacokinetics and pharmacodynamics in subjects with moderate renal impairment and end-stage renal disease. J Clin Pharm Ther 34: 585-594, 2009.

27. Linthorst GE, Folman CC, van Olden RW, von dem Borne AE. Plasma thrombopoietin levels in patients with chronic renal failure. Hematol J 3: 38-42, 2002.

28. Desta Z, Zhao X, Shin JG, Flockhart DA. Clinical significance of the cytochrome P450 2C19 genetic polymorphism. Clin Pharmacokinet 41: 913-958, 2002.

(C) 2014 The Japanese Society of Internal Medicine

http://www.naika.or.jp/imonline/index.html 